\section{Focus on ECGs:}

Case \#6

Mark Pollet, MD

Mohammad Saeed, MD

Section Editors:

Yochai Birnbaum, MD

Mohammad Saeed, MD

James M. Wilson, MD

From: Department of Cardiology (Dr. Pollet), Baylor College of Medicine; and Department of Cardiology (Dr. Saeed), Texas Heart Institute and CHI St. Luke's Health-Baylor St. Luke's Medical Center; Houston, Texas 77030

\section{Address for reprints:} Mark Pollet, MD, Department of Cardiology, Baylor College of Medicine, One Baylor Plaza,

Houston, TX 77030

E-mail: pollet@bcm.edu

\section{Proarrhythmic Antiarrhythmic}

A 56-year-old man with a history of atypical atrial flutter related to atrial septal defect repair presented at the emergency department with palpitations and light-headedness. An electrocardiogram (ECG) was performed (Fig. 1). He had undergone an ablation procedure and therapy with metoprolol and flecainide. He had a history of cardiac arrest and had received a Teligen ${ }^{\circledR}$ model E110 dual-chamber implantable cardioverter-defibrillator (ICD) (Boston Scientific Corporation; Natick, Mass). The ICD was programmed in DDD mode, with a lower rate limit of 60 beats/min and an upper limit of 120 beats/min. Ventricular tachycardia therapy was set to begin at 210 beats/min, and ventricular fibrillation therapy at $>230$ beats/min.

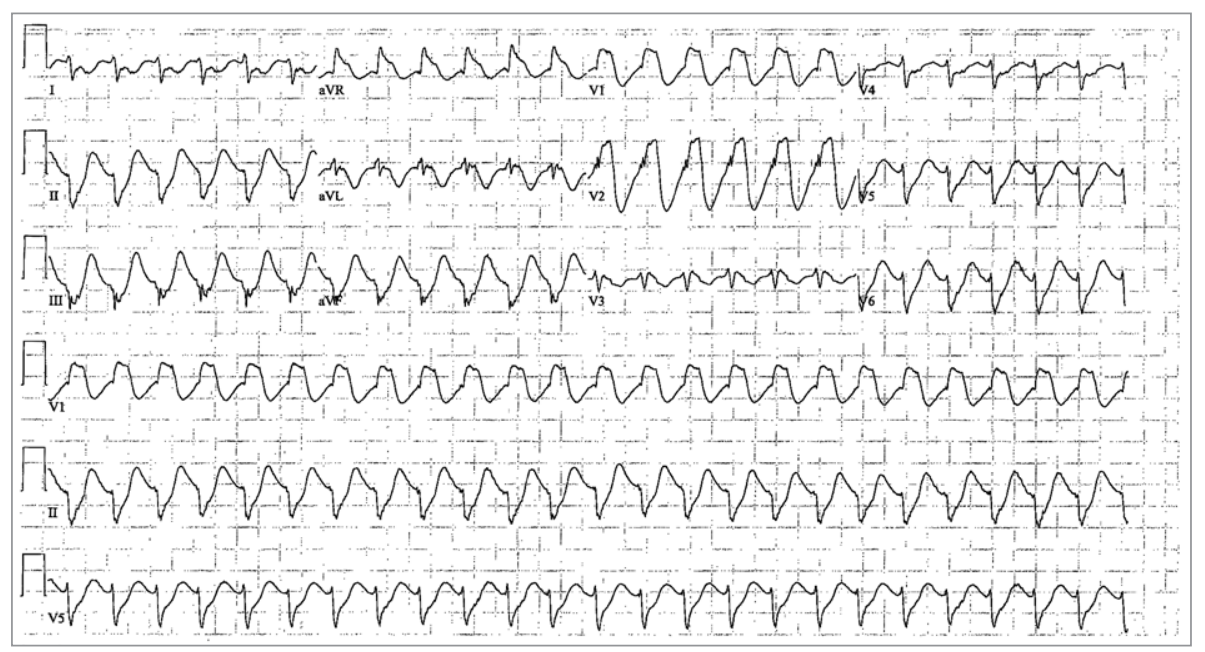

Fig. 1

\section{How can the cause of the tachycardia be explained?}

A) Organization of atrial rhythm with 1:1 conduction from medication effect

$B$ ) Atrioventricular (AV) nodal reentry tachycardia with aberrancy

C) Ventricular tachycardia with origin from the left bundle related to medication effect

D) Pacemaker-mediated tachycardia

See next page for the answer, as well as a link to the Focus on ECGs blog, where you can participate in a moderated discussion. 


\section{FOCUS ON ECGs: ANSWER \#6}

\section{Answer}

\section{A) Organization of atrial rhythm with 1:1 conduction from medication effect}

Given the patient's history and medications, choice A is most likely. Figure 2, a baseline atrial-paced ECG, shows the patient's intrinsic QRS morphology, which is similar to that in the ECG in Figure 1. This morphology strongly supports a diagnosis of supraventricular tachycardia (SVT).

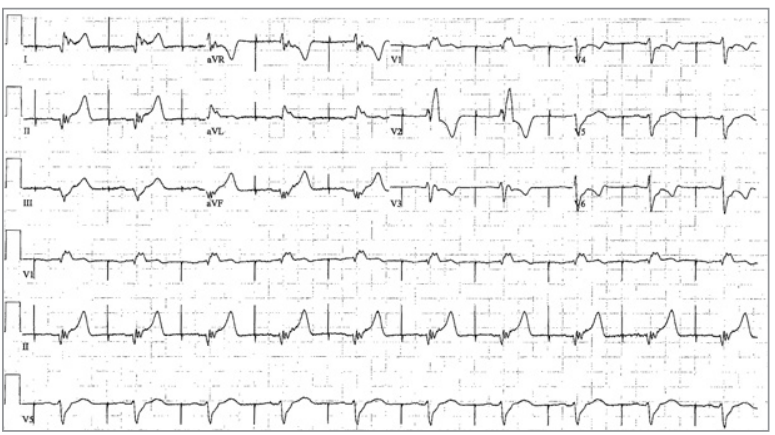

Fig. 2

Interrogation of the patient's ICD revealed 1:1 conduction, confirming the diagnosis of SVT (Fig. 3).

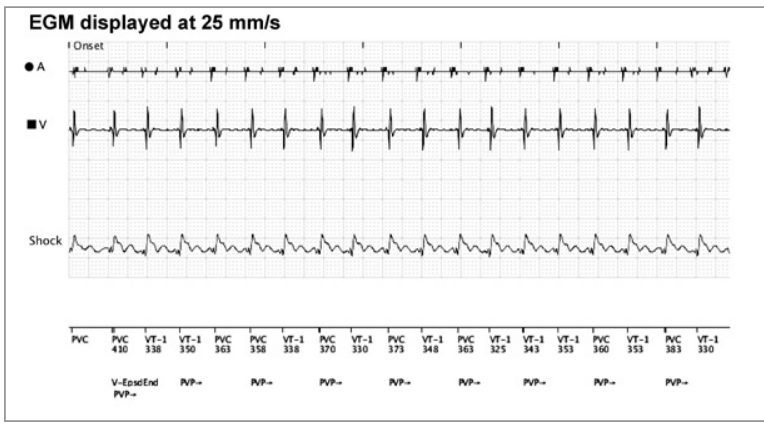

Fig. 3

Flecainide can "organize" atrial fibrillation or retard atrial flutter to a cycle length that is delayed enough to enable the AV node to conduct 1:1 signals. This can paradoxically cause a faster ventricular rate, which might compromise circulation.

Flecainide is a class IC antiarrhythmic agent that inhibits sodium-channel activation and thus slows conduction velocities. It is often used to maintain sinus rhythm in paroxysmal atrial fibrillation and atrial flutter, and it can be used as a "pill-in-the-pocket" medication for selected patients. ${ }^{2}$
At atrial rates approaching 300 to 400 beats $/ \mathrm{min}$, the AV node often becomes refractory, allowing only $2: 1$ or 3:1 conduction and ventricular rates of 120 to 150 beats $/ \mathrm{min}$. As flecainide works to slow the atrial rate to less than 200 beats $/ \mathrm{min}$, the AV node is more apt to conduct $1: 1$, possibly causing ventricular rates to exceed 150 beats $/ \mathrm{min}$. Simultaneous $\beta$-blocker therapy is often recommended to reduce this effect. ${ }^{3}$

Other rhythm disturbances related to flecainide are AV block, sick sinus syndrome, and ventricular tachycardia. Use of flecainide is avoided in structural heart disease related to ischemia, cardiomyopathy, hypertrophy, and certain valvular diseases.

After the patient underwent repeat ablation for atypical atrial flutter, he was asymptomatic with no recurrence.

\section{References}

1. Falk RH. Proarrhythmia in patients treated for atrial fibrillation or flutter [published erratum appears in Ann Intern Med 1992;117(5):446]. Ann Intern Med 1992;117(2):141-50.

2. Alboni P, Botto GL, Baldi N, Luzi M, Russo V, Gianfranchi $\mathrm{L}$, et al. Outpatient treatment of recent-onset atrial fibrillation with the "pill-in-the-pocket" approach. N Engl J Med 2004; 351(23):2384-91.

3. January CT, Wann LS, Alpert JS, Calkins H, Cigarroa JE, Cleveland JC Jr, et al. 2014 AHA/ACC/HRS guideline for the management of patients with atrial fibrillation: a report of the American College of Cardiology/American Heart Association Task Force on Practice Guidelines and the Heart Rhythm Society [published erratum appears in J Am Coll Cardiol 2014; 64(21):2305-7]. J Am Coll Cardiol 2014;64(21):e1-76.

To participate in a moderated discussion of this case, go to THIJournal.blogspot.com. Two weeks from the original posting date, the discussion will close, but the comments will remain online for reference. 